\title{
UNFAMILIAR PRESENTATION OF RHINOSPORIDIOSIS
}

\author{
G. Sriram ${ }^{1}$, M. Subhashini², Rizwan Mohammed Rafeeque3, P. Ganesh Babu ${ }^{4}$
}

${ }^{1}$ Assistant Professor, Department of ENT, Vinayaka Missions Medical College and Hospital, Karaikal.

2Postgraduate Student, Department of ENT, Vinayaka Missions Medical College and Hospital, Karaikal.

${ }^{3}$ Postgraduate Student, Department of ENT, Vinayaka Missions Medical College and Hospital, Karaikal.

${ }_{4}^{4}$ Postgraduate Student, Department of ENT, Vinayaka Missions Medical College and Hospital, Karaikal.

\section{ABSTRACT}

\section{BACKGROUND}

Rhinosporidiosis is a chronic inflammatory disease common in India and Sri Lanka. Its manifestations are mostly nasal, though extranasal ones in head and neck region are not rare. Occasionally, these presentations lead to diagnostic dilemma. Here, we present one case with its associated confusions in extranasal manifestations. The patient presented with polypoidal mass hanging from nasopharynx into oropharynx. Two nasopharyngeal masses were removed successfully followed by cauterisation of the base. The experience about the various manifestations and diagnostic problems is discussed here.

\section{KEYWORDS}

Rhinosporidiosis, Bleeding Polyp, Basal Cauterisation.

HOW TO CITE THIS ARTICLE: Sriram G, Subhashini M, Rafeeque RM, et al. Unfamiliar presentation of rhinosporidiosis. J. Evolution Med. Dent. Sci. 2017;6(9):738-740, DOI: 10.14260/Jemds/2017/159

\begin{abstract}
BACKGROUND
Rhinosporidiosis is a chronic, granulomatous disease process caused by fungus-like organism known as Rhinosporidium seeberi. It is yet an unclassified fungus. [1] Rhinosporidiosis is characterised by reddish polypoidal mass, which are hyperplasic and friable and sometimes it may be sessile. The disease mostly affects nasal cavity mainly involving anterior part of nasal septum, vestibule and also nasopharynx, but extranasal involvement, particularly in the lower aerodigestive tract including the tracheobronchial tree is rare. The organism has an affinity for the mucous membrane of the nose and nasopharynx. It thrives in hot tropical climates of the endemic zones, i.e. South India and Sri Lanka.[2] Apart from nasal cavity the other sites of involvement are lips, palate, uvula, conjunctiva, larynx, trachea, penis, vagina and even the bone. ${ }^{[3,4]}$ The diagnosis is usually delayed and difficult when extranasal sites are involved. Occupational and personal history are helpful in achieving diagnosis and histopathological examination is also necessary.
\end{abstract}

\section{MATERIALS AND METHODS}

Patient were from the Department of Otolaryngology VMMCH. A 45-year-old, Mariyappan, male patient residing at mayiladudurai farmer by occupation with $\mathrm{C} / \mathrm{O}$ bilateral nasal obstruction for 7 years and difficulty in swallowing and loss of sensation of smell for 6 years. Clinical presentation was left-sided obstruction was more and which was insidious in onset and progressive in nature, difficulty in swallowing was for both solid and liquid which aggravated on lying down position. History of pond bath, snoring during sleep and change in voice present.

Financial or Other, Competing Interest: None.

Submission 23-12-2016, Peer Review 16-01-2017,

Acceptance 23-01-2017, Published 30-01-2017.

Corresponding Author:

Dr. M. Subhashini,

\#06, Ammayar Nagar, Rajaji Street,

Kheezakasakudy,

Karaikal-609609.

E-mail: drsubha28@gmail.com

DOI: $10.14260 /$ jemds $/ 2017 / 159$
No history of bleeding, which is very unusual for such a huge mass with no systemic illness; personal history was normal. Habituation is alcoholic since 25 years, $180 \mathrm{~mL}$ per day, not a smoker or other snuffing or betel chewing. Family history, not relevant.

DNE - There were multiple small polypoidal mass involving both nasal cavity, choane could not be visualised on both sides. Septum deviated to left side.

VDL - Two mass hanging over posterior pharyngeal wall and it seems to extend till epiglottis. Patient on hawking gets the mass to oral cavity (Fig. 1).

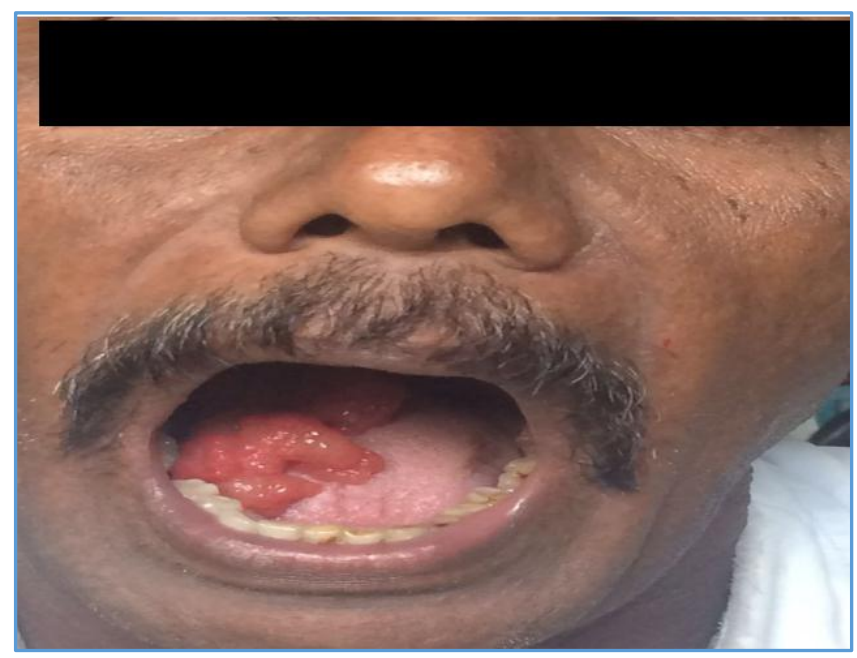

Figure 1

After initial clinical examination, the patients were subjected to routine laboratory investigations for operative fitness and CT scan of the relevant area of involvement of atypical extranasal presentation.

The patient was operated by a combined approach external for oropharynx and hypopharynx in Roses position (Fig. 2) and internal for the nasal mass by nasal endoscopy. In the case of polypoidal lesions involving the nasopharynx, which were at times difficult to differentiate clinically from 
antrochoanal polyp (Fig. 3) and posed a greater diagnostic dilemma. The masses were removed meticulously and their stalks were electrocauterised with bipolar system.

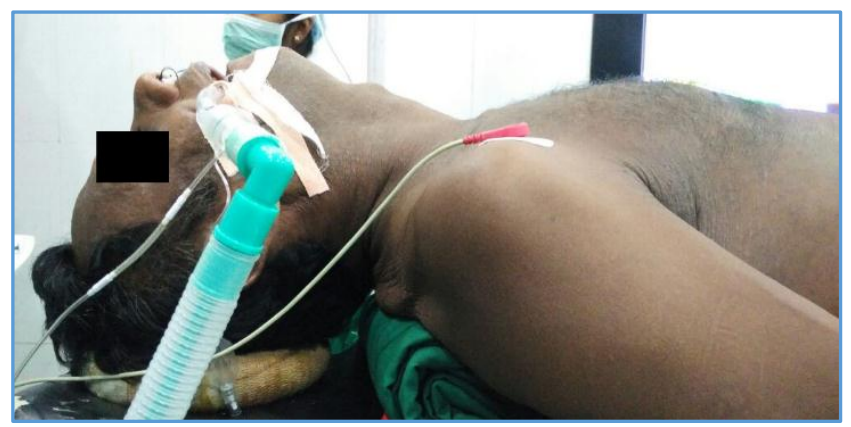

Figure 2

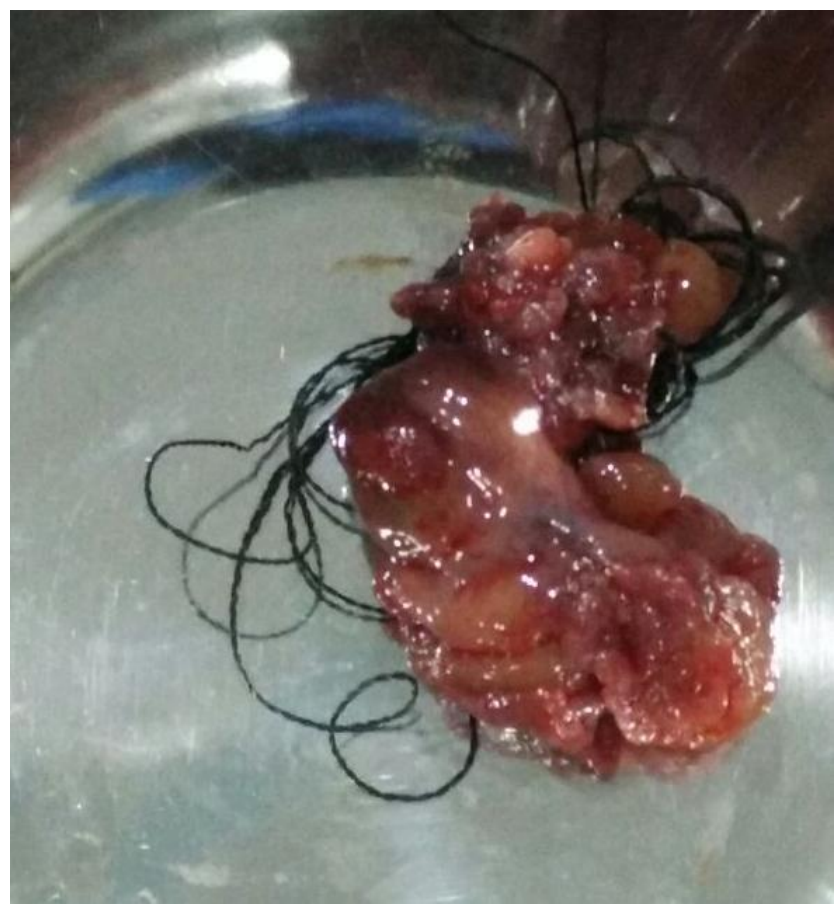

Figure 3

\section{DISCUSSION}

The first case of Rhinosporidiosis was reported by Malbran in 1892 and was published by Seeber in 1900, who thought that they are protozoan spores, ${ }^{[5]}$ that is why it was named as Rhinosporidium seeberi. But in 1923, Ashworth[6] described the fungus life cycle. In 1992, Ahluwalia discarded of its fungal aetiology[7] and renamed the structures as nodular bodies. Rhinosporidiosis is four times more common in males with usual age of presentation between 10 and 40 years.[3] Infection of nose and nasopharynx is observed in $85 \%$ of persons with rhinosporidiosis. Other sites involved are eye (9\%), penile urethra, external ear and bones.[3] Macroscopically, the typical lesion of Rhinosporidiosis is fleshy, vascular, polypoidal and granulomatous, studded with grayish white dots, present on surface of lesion.[8] On histopathology, large round chitinous structure filled with endospores are seen.[9] Within 10 days, a sporangium is formed from this endospore through an intermediate trophozoite stage. The organism can be observed by staining the smears with routine haematoxylin and eosin stain. The most effective treatment is wide excision with a cutting diathermy and cauterisation of the base of lesion. Previously, antifungal agents were also used but were ineffective.[10] The principal site of infection is usually the nasal cavity; where it manifests by a bleeding polyp. Endoscopic visualisation revealed the attachment of mass at posterior end of the septum and nasopharynx. These presentations created confusion in our observation, the possibility of Rhinosporidiosis was in our mind. Even after the CT scan, we were not sure about the diagnosis. So after the endoscopic removal of mass, the base was cauterised. The histopathology report came in favour of Rhinosporidiosis.

Treatment of Rhinosporidiosis is a problem. Diathermy excision is considered to be the treatment of choice.[11] As the lesion is very vascular, we considered a biopsy or excision rather dangerous. The clinical presence of single lesion in nasal cavity and multiple lesions in the other parts of respiratory tract were proof enough of the diagnosis. Diathermy excision is an acceptable treatment modality in cases of nose and nasopharyngeal presentations. But when there is involvement of the tracheobronchial tree, a more radical approach may be considered. Now as Laser is available at some centres, the choice of treatment may be cauterisation with Laser through a bronchoscope. However, Laser is still not freely available in India and Sri Lanka where Rhinosporidiosis is endemic. In case of laryngeal involvement, recurrence was noted. The available literature suggests that in that case it would have been appropriate to go for Laser surgery.

\section{CONCLUSION}

Atypical presentation of rhinosporidiosis in head and neck region is rare. Very often, this atypical presentation causes dilemma in diagnosis and creates confusion. Till now surgical excision and cauterisation of the base remains the mainstay of treatment. This is a case of non-bleeding rhinosporidial polypoidal mass.

\section{REFERENCES}

[1] Emmons CW, Binford CH, Utz JP, et al. Medical mycology. $3^{\text {rd }}$ edn. Philadelphia: Lea and Febiger 1977:464-70.

[2] Khoo JJ, Kumar KS. Rhinosporidiosis presenting as recurrent nasal polyps. Med J Malaysia 2003;58(2):2825.

[3] Franca GV, Gomes CC, Sakano E, et al. Nasal rhinosporidiosis in children. J Pedatr (Rio J) 1994;70(5):299-301.

[4] Makannavar JH, Chavan SS. Rhinosporidiosis: a clinicopthological study of 34 cases. Indian J Pathol Microbiol 2001;44(1):17-21.

[5] Seeber GR. Un nuevo esporozoaris parasito del hombre dos casos encontrados en polipos nasales. Thesis University Nac, de Buenos Aires 1900:p 620.

[6] Ashworth JH. On rhinosporidium seeberi with special reference to its sporulation and affinities. Trans R Soc Edinburgh 1924;53(2):301-42.

[7] Ahluwalia KB. New interpretations in rhinosporidiosis, enigmatic disease of last nine decades. J Submicrosc Cytol Pathol 1992;24(1):109-14. 
[8] Sood NN, Rao SN. Rhinosporidium granuloma of the conjuctiva. J Pediatr Ophthalmol 1969;6(3):142-4.

[9] Kuriakose ET. Oculosporidiosis, rhinosporidiosis of the eye. Br J Ophthalmol 1963;47:346-9.
[10] Job A, Venkateswaran S, Mathan M. Medical therapy of rhinosporidiosis with dapsone. J Laryngol Otol 1993;107(9):809-12.

[11] Khan AA, Khaleque KA, Huda MN. Rhinosporidiosis of the nose. J Laryngol Otol 1969;83(5):461-73. 